\title{
Risk of intracranial haemorrhage in antidepressant users with concurrent use of non-steroidal anti-inflammatory drugs: nationwide propensity score matched study
}

\author{
Ju-Young Shin, ${ }^{1}$ Mi-Ju Park, ${ }^{1}$ Shin Haeng Lee, ${ }^{1}$ So-Hyun Choi, ${ }^{1}$ Mi-Hee Kim, ${ }^{1}$ Nam-Kyong Choi, ${ }^{2}$ \\ Joongyub Lee, ${ }^{2}$ Byung-Joo Park ${ }^{3}$
}

${ }^{1}$ Korea Institute of Drug Safety and Risk Management, 110-750 Seoul, Korea

${ }^{2}$ Medical Research Collaborating Center, Seoul National University College of Medicine and Seoul National University Hospital, 110-799

Seoul, Korea

${ }^{3}$ Department of Preventive Medicine, Seoul National University College of Medicine, 110-799 Seoul, Korea

Correspondence to: B-J Park bjpark@snu.ac.kr

Cite this as: BMJ 2015;351:h3517 doi: 10.1136/bmj.h3517

Accepted: 16 June 2015

\section{ABSTRACT}

\section{OBJECTIVE}

To define the risk of intracranial haemorrhage among patients treated with antidepressants and non-steroid anti-inflammatory drugs (NSAIDs), compared with the risk among those treated with antidepressants without NSAIDs.

\section{DESIGN}

Retrospective nationwide propensity score matched cohort study.

\section{SETTING}

Korean nationwide health insurance database between 1 January 2009 and 31 December 2013.

\section{PARTICIPANTS}

Patients who began receiving antidepressants for the first time (index date) without a history of having received a prescription for antidepressants during the preceding year. Patients who had been diagnosed as having cerebrovascular diseases within a year before the index date were excluded.

\section{MAIN OUTCOME MEASURE}

Time to first hospital admission with intracranial haemorrhage within 30 days after drug use. Matched Cox regression models were used to compare the risk of intracranial haemorrhage among patients who were treated with antidepressants with and without NSAIDs, after propensity score matching with a 1:1 ratio.

RESULTS

After propensity score estimation and matching in a 1:1 ratio, the cohort used in the analysis included 4145226 people. The 30 day risk of intracranial haemorrhage during the entire study period was higher for combined use of antidepressants and NSAIDs than for use of antidepressants without NSAIDs (hazard ratio $1.6,95 \%$ confidence interval 1.32 to 1.85 ). No statistically meaningful differences were found in risk of intracranial haemorrhage between the antidepressant drug classes.

\section{WHAT IS ALREADY KNOWN ON THIS TOPIC}

Antidepressants and non-steroidal anti-inflammatory drugs (NSAIDs) are generally believed to each increase the risk of abnormal bleeding

However, very little is known about the risk of intracranial haemorrhage associated with the combined use of antidepressants and NSAIDs

\section{WHAT THIS STUDY ADDS}

Combined use of antidepressants and NSAIDs was associated with an increased risk of intracranial haemorrhage within 30 days of initial combination

\section{CONCLUSIONS}

Combined use of antidepressants and NSAIDs was associated with an increased risk of intracranial haemorrhage within 30 days of initial combination.

\section{Introduction}

Depression produces the greatest decrement in health of all common chronic conditions, ${ }^{1}$ and depression in older people is an important public health problem. ${ }^{2}$ Antidepressants can help depressive patients effectively, but concern exists that antidepressants may interact unfavourably with non-steroidal anti-inflammatory drugs (NSAIDs). ${ }^{34}$

Antidepressants, especially selective serotonin reuptake inhibitors, and NSAIDs are each thought to increase the risk of abnormal bleeding. ${ }^{56}$ According to the results of a meta-analysis in 2008, the odds ratio of upper gastrointestinal haemorrhage was 2.36 (95\% confidence interval 1.44 to 3.85 ) for selective serotonin reuptake inhibitors alone and 6.33 (3.40 to 11.82) with concomitant NSAIDs, ${ }^{7}$ although controversy exists about whether the risk of gastrointestinal bleeding increases when they are prescribed together, compared with their use alone. ${ }^{89}$

Unlike for gastrointestinal bleeding, neither selective serotonin reuptake inhibitors nor NSAIDs alone have been found to be associated with an increased risk of intracranial haemorrhage. ${ }^{10-13}$ However, little is known about the risk of intracranial haemorrhage associated with the combined use of antidepressants and NSAIDs. We sought to estimate the risk of intracranial haemorrhage among patients who were treated with both antidepressants and NSAIDs, compared with the risk among those treated with antidepressants without NSAIDs.

\section{Methods}

Data source

We used the Korean Health Insurance Review and Assessment Service database for this study. The National Health Insurance programme started in Korea in 1977 and achieved universal coverage of the population by $1989 .{ }^{14}$ All Koreans are covered by the programme. Accordingly, the database contains all information on healthcare use and prescribed drugs for approximately 50 million Koreans.

We obtained the claims data for the patients who were prescribed at least one antidepressant drug from 1 January 2009 to 31 December 2013. The database included an unidentifiable code representing each patient together with age, sex, diagnosis, ambulatory 
care, hospital admissions, and dates of visits. ${ }^{15}$ In addition, prescribed drug information included the generic name, prescription date, and duration. The diagnosis was coded according to the international classification of disease, 10th revision (ICD-10). A previous validation study compared the diagnoses derived from the database with the actual diagnoses in the patients' medical records. The overall positive predictive value of the diagnoses was $83.4 \% .^{16}$

\section{Patient involvement and study population}

There was no patient involvement in this study. The study population was composed of antidepressant treated patients. We included new users of antidepressants who took antidepressants for the first time between 1 January 2010 and 31 December 2013 (index date) without a history of having received a prescription for antidepressants during the preceding year. By including only new users, we could ignore the influence of previous antidepressant treatment. We excluded patients who had been diagnosed as having cerebrovascular diseases (ICD-10: I60-I68, G45, G46) as their primary or secondary diagnosis within a year before the index date. We also excluded patients who were over the age of 99, had a diagnosis of intracranial haemorrhage on the index date, or took prescriptions for more than one antidepressant on the index date and those whose index date was the last day of the study. In addition, we excluded patients whose index date came after the date of death (ICD-10: I46.1, I46.9, R96, R98, R99) (figure). Antidepressants included tricyclic antidepressants, selective serotonin reuptake inhibitors, serotonin-norepinephrine reuptake inhibitors, monoamine oxidase inhibitors, and others. ${ }^{17}$ Antidepressants

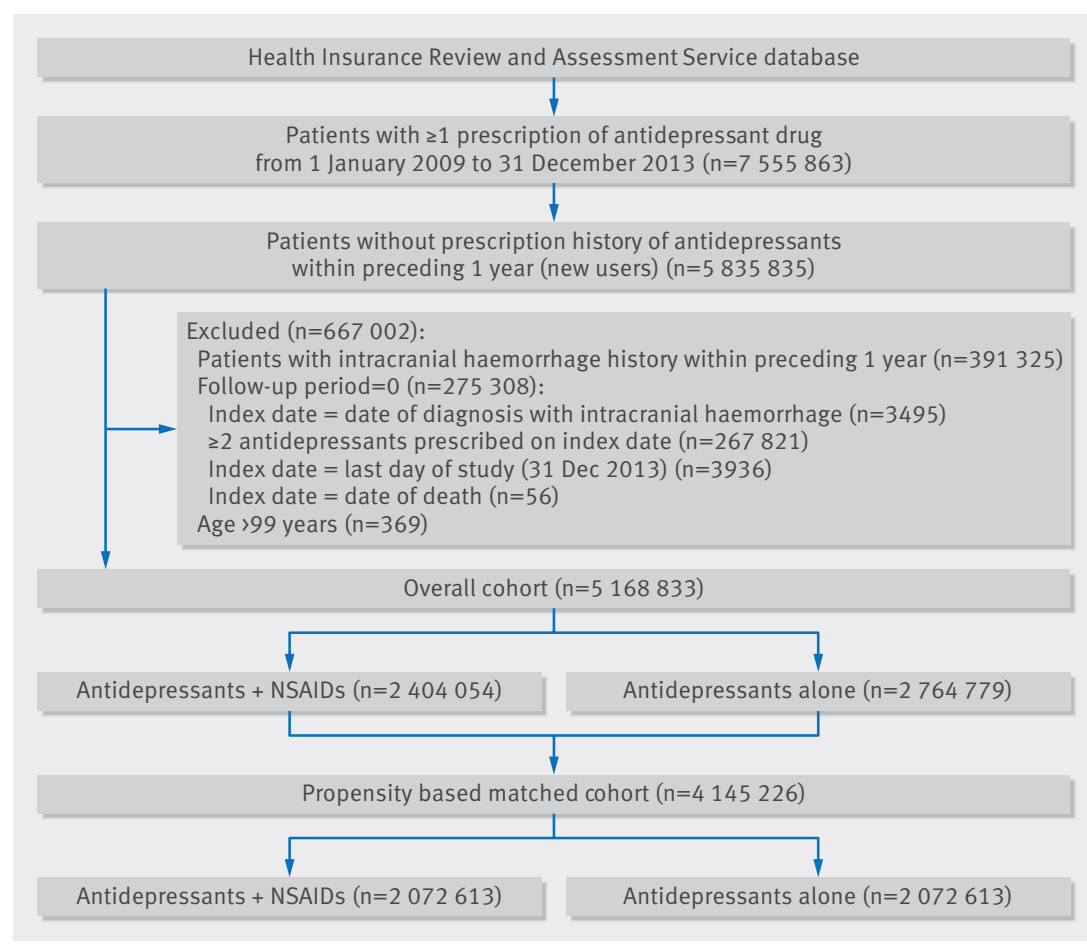

Selection of study participants from Health Insurance Review and Assessment Service database in retrospective cohort design. NSAID=non-steroidal anti-inflammatory drug included in "others" were bupropion, hypericin, mirtazapine, tianeptine, and trazodone.

\section{Combined use of antidepressants and NSAIDs}

Among antidepressant treated patients, we obtained their NSAID prescriptions by using the Anatomical Therapeutic Chemical codes (M01A, N02BA). We defined combined use of antidepressants and NSAIDs as the prescription of at least one NSAID during the defined 30 day follow-up of antidepressants.

\section{Follow-up to intracranial haemorrhage}

We defined the outcome as time to first hospital admission with intracranial haemorrhage (ICD-10: I60-62) as the primary or secondary diagnosis within 30 days' follow-up after the index date. The index date was the date of newly prescribed antidepressants. We assumed follow-up of antidepressant to last for seven days after the final prescription in a continuous course of treatment. We considered follow-up to have started on the index date and to have ended on the date of first hospital admission with intracranial haemorrhage within 30 days, the date the patient switched to another antidepressant, the date of discontinuation, or the last day of the study. We treated death as a competing risk.

\section{Potential confounders}

Age, sex, comorbidity, and co-medication are all possible confounders of the association between antidepressant use and intracranial haemorrhage. We defined information on comorbidity and co-medication according to previous diagnoses and the use of drugs within one year before the index date. We calculated the modified Charlson index to estimate the severity of disease according to previous diagnoses within one year before the index date. ${ }^{18}$ We selected as confounders any comorbidities that may influence the risk of intracranial haemorrhage, which included diabetes, chronic obstructive pulmonary disease, hypertension, osteoarthritis, rheumatoid arthritis, osteoporosis, alcohol related disorder, ischaemic heart disease, chronic kidney disease, peptic ulcer, dementia, non-alcoholic liver disease, schizophrenia, neoplasm, HIV infection, transplantation, atrial fibrillation, heart failure, disease of arteries, and disease of veins. Low dose acetylsalicylic acid (Anatomical Therapeutic Chemical code: B01AC06), steroids (H02AB), warfarin (B01AA03), heparin (B01AB), platelet aggregation inhibitors (B01AC), antithrombotic enzymes (B01AD), direct thrombin inhibitors (B01AE), direct factor Xa inhibitors (B01AF), and other antithrombotic agents (B01AX) were also selected as confounders because they might increase the risk of intracranial haemorrhage through their action on haemostasis.

\section{Statistical analysis}

We estimated the propensity scores for adding NSAIDs to antidepressants without regard to outcomes by multiple logistic regression analysis using the following variables: age category, sex, Charlson index category, comorbidity, and co-medication (table 1). We assessed 


\begin{tabular}{|c|c|c|c|c|c|c|}
\hline \multirow[b]{2}{*}{ Characteristic } & \multicolumn{3}{|l|}{ Overall cohort } & \multicolumn{3}{|c|}{ Propensity based matched cohort } \\
\hline & $\begin{array}{l}\text { Antidepressants } \\
\text { only ( } n=2764779)\end{array}$ & $\begin{array}{l}\text { Antidepressants + } \\
\text { NSAIDs }(n=2 \quad 404054)\end{array}$ & $\begin{array}{l}\text { Standardised } \\
\text { difference }\end{array}$ & $\begin{array}{l}\text { Antidepressants } \\
\text { only }(n=2072613)\end{array}$ & $\begin{array}{l}\text { Antidepressants + } \\
\text { NSAIDs }(\mathrm{n}=2072613)\end{array}$ & $\begin{array}{l}\text { Standardised } \\
\text { difference }\end{array}$ \\
\hline \multicolumn{7}{|l|}{ Demographics } \\
\hline \multicolumn{7}{|l|}{ Age group (years): } \\
\hline Mean (SD) age & $48.4(18.4)$ & $54.2(16.6)$ & \multirow{6}{*}{0.328} & $52.2(16.6)$ & $52.3(16.6)$ & \multirow{6}{*}{0.006} \\
\hline $0-19$ & $204367(7.4)$ & $61672(2.6)$ & & $61071(2.9)$ & $61656(3.0)$ & \\
\hline $20-39$ & $654648(23.7)$ & $400720(16.7)$ & & 397027 (19.2) & 396371 (19.1) & \\
\hline $40-64$ & $1329547(48.1)$ & $1228226(51.1)$ & & $1103536(53.2)$ & $1097930(53.0)$ & \\
\hline $65-84$ & $538863(19.5)$ & $675080(28.1)$ & & $480887(23.2)$ & $487269(23.5)$ & \\
\hline$\geq 85$ & $37354(1.4)$ & $38356(1.6)$ & & $30092(1.5)$ & $29387(1.4)$ & \\
\hline Male sex & $1114940(40.3)$ & $869041(36.1)$ & -0.013 & $805365(38.9)$ & $795345(38.4)$ & 0.001 \\
\hline \multicolumn{7}{|l|}{ Charlson comorbidity index: } \\
\hline Median (interquartile range) & $(0(0-1)$ & $1(0-1)$ & \multirow{6}{*}{0.073} & $1(0-1)$ & $1(0-1)$ & \multirow{6}{*}{0.002} \\
\hline 0 & $1394275(50.4)$ & $1068932(44.5)$ & & $981641(47.4)$ & $978534(47.2)$ & \\
\hline 1 & $1103031(39.9)$ & $1091536(45.4)$ & & $884536(42.7)$ & $887641(42.8)$ & \\
\hline 2 & $67160(2.4)$ & $54683(2.3)$ & & $51125(2.5)$ & $49966(2.4)$ & \\
\hline 3 & $174408(6.3)$ & $168568(7.0)$ & & $136768(6.6)$ & $137769(6.6)$ & \\
\hline$\geq 4$ & $25905(0.9)$ & $20335(0.8)$ & & $18543(0.9)$ & $18703(0.9)$ & \\
\hline \multicolumn{7}{|c|}{ History of comorbidities in previous year } \\
\hline Diabetes & $317803(11.5)$ & $328821(13.7)$ & 0.066 & $259458(12.5)$ & $262238(12.7)$ & 0.004 \\
\hline Chronic obstructive pulmonary disease & $365336(13.2)$ & 389601 (16.2) & 0.085 & $309763(14.9)$ & $311016(15.0)$ & 0.002 \\
\hline Hypertension & $639433(23.1)$ & $722923(30.1)$ & 0.158 & $550910(26.6)$ & 556677 (26.9) & 0.006 \\
\hline Dyslipidaemia & $93395(3.4)$ & $96412(4.0)$ & 0.034 & $77404(3.7)$ & $77529(3.7)$ & 0.000 \\
\hline Osteoarthritis & $426466(15.4)$ & $734486(30.6)$ & 0.365 & $422387(20.4)$ & $426940(20.6)$ & 0.005 \\
\hline Rheumatoid arthritis & $40484(1.5)$ & $90765(3.8)$ & 0.145 & $40156(1.9)$ & $41115(2.0)$ & 0.003 \\
\hline Osteoporosis & $167656(6.1)$ & $256709(10.7)$ & 0.167 & $159519(7.7)$ & $162192(7.8)$ & 0.005 \\
\hline Alcohol related disorder & $63306(2.3)$ & $40934(1.7)$ & -0.042 & $36575(1.8)$ & $38482(1.9)$ & 0.007 \\
\hline Ischaemic heart disease & $139364(5.0)$ & $138095(5.7)$ & 0.031 & $110828(5.3)$ & $112211(5.4)$ & 0.003 \\
\hline Chronic kidney disease & $43487(1.6)$ & $31496(1.3)$ & -0.022 & $27789(1.3)$ & $28242(1.4)$ & 0.002 \\
\hline Peptic ulcer & $477039(17.3)$ & $475766(19.8)$ & 0.065 & $384642(18.6)$ & $388098(18.7)$ & 0.004 \\
\hline Dementia & $39397(1.4)$ & $24019(1.0)$ & -0.039 & $21360(1.0)$ & $22918(1.1)$ & 0.007 \\
\hline Non-alcoholic liver disease & $237558(8.6)$ & $215575(9.0)$ & 0.013 & $182140(8.8)$ & $182549(8.8)$ & 0.001 \\
\hline Schizophrenia & $40604(1.5)$ & $11454(0.5)$ & -0.101 & $10559(0.5)$ & $11432(0.6)$ & 0.006 \\
\hline Neoplasm & $390653(14.1)$ & $352173(14.6)$ & 0.015 & 306991 (14.8) & $304632(14.7)$ & -0.003 \\
\hline HIV infection & $160(0.0)$ & $92(0.0)$ & -0.003 & $81(0.0)$ & $87(0.0)$ & 0.000 \\
\hline Transplantation & $2406(0.1)$ & $1012(0.0)$ & -0.018 & $1094(0.1)$ & $1010(0.0)$ & -0.002 \\
\hline Atrial fibrillation & $2383(0.1)$ & $2168(0.1)$ & 0.001 & $1786(0.1)$ & $1820(0.1)$ & 0.001 \\
\hline Heart failure & $27399(1.0)$ & $29118(1.2)$ & 0.021 & $22068(1.1)$ & $22548(1.1)$ & 0.002 \\
\hline Disease of arteries & $144540(5.2)$ & $181391(7.5)$ & 0.095 & $130172(6.3)$ & $131913(6.4)$ & 0.003 \\
\hline Disease of veins & $125143(4.5)$ & $130618(5.4)$ & 0.042 & $105024(5.1)$ & $105291(5.1)$ & 0.001 \\
\hline \multicolumn{7}{|l|}{ Drug use in previous year } \\
\hline Low dose aspirin (B01AC06) & $307216(11.1)$ & $339112(14.1)$ & 0.090 & $259218(12.5)$ & $262403(12.7)$ & 0.005 \\
\hline Warfarin (B01AA) & $1345295(48.7)$ & $1466106(61.0)$ & 0.250 & $1174364(56.7)$ & $1180344(56.9)$ & 0.006 \\
\hline Heparin group (B01AB) & $13362(0.5)$ & $11076(0.5)$ & -0.003 & $9507(0.5)$ & $9623(0.5)$ & 0.001 \\
\hline Platelet aggregation inhibitors (B01AC) & $61082(2.2)$ & $56828(2.4)$ & 0.010 & $45986(2.2)$ & $46428(2.2)$ & 0.001 \\
\hline Antithrombotic enzymes (B01AD) & $149681(5.4)$ & $168921(7.0)$ & 0.067 & $125779(6.1)$ & $127661(6.2)$ & 0.003 \\
\hline Direct thrombin inhibitors (B01AE) & $1002(0.0)$ & $711(0.0)$ & -0.004 & $662(0.0)$ & $656(0.0)$ & 0.000 \\
\hline Direct factor Xa inhibitors (B01AF) & $72(0.0)$ & $54(0.0)$ & -0.001 & $50(0.0)$ & $50(0.0)$ & 0.000 \\
\hline Other antithrombotic agents (B01AX) & $1294(0.0)$ & $4388(0.2)$ & 0.040 & $1289(0.1)$ & $1360(0.1)$ & 0.001 \\
\hline Steroids (H02AB) & $272(0.0)$ & $679(0.0)$ & 0.013 & $268(0.0)$ & $268(0.0)$ & 0.000 \\
\hline \multicolumn{7}{|l|}{ Index year } \\
\hline 2010 & $709825(25.7)$ & $629977(26.2)$ & \multirow{4}{*}{-0.013} & $536952(25.9)$ & $538817(26.0)$ & \multirow{4}{*}{-0.003} \\
\hline 2011 & $726262(26.3)$ & $631551(26.3)$ & & $541168(26.1)$ & $542479(26.2)$ & \\
\hline 2012 & $705962(25.5)$ & $609967(25.4)$ & & $527004(25.4)$ & $526486(25.4)$ & \\
\hline 2013 & $622730(22.5)$ & $532559(22.2)$ & & $467489(22.6)$ & $464831(22.4)$ & \\
\hline
\end{tabular}

model discrimination with the $\mathrm{c}$ statistic. Matching was done using the Greedy $5 \cdots 1$ digit matching macro with the estimated propensity score. ${ }^{19}$ We used a standardised difference to compare baseline characteristics between patients who were treated with antidepressants without NSAIDs and those treated with antidepressants and NSAIDs. ${ }^{20}$ We calculated Cohen's $d$ as the difference between two sample means divided by a pooled standard deviation for the data. We defined imbalance as an absolute value greater than 0.1.21 
We calculated the incidence rate per 1000 person years by dividing the number of intracranial haemorrhage events by the total number of person years at risk and multiplying the result by 1000 and calculated the 95\% confidence interval assuming a Poisson distribution. For construction of the multivariable model, we included variables that achieved statistical significance in the likelihood ratio test. The final model included dementia, warfarin, heparin group, and steroids as the adjusting variables. We assessed the status of combined use of NSAIDs and covariates on a daily basis during the follow-up period for the time varying covariates. We used matched Cox regression models to estimate hazard ratios and their 95\% confidence intervals for intracranial haemorrhage with time varying covariates in the propensity based matched cohort. By using this model, we could obtain an unbiased estimate of the change in the hazard of intracranial haemorrhage because of the concomitant use of antidepressants and NSAIDs. ${ }^{22}$ Competing risks arise when patients are exposed to several causes and failure due to one cause excludes failure due to other causes..$^{23}$ In our study, we treated death as a competing risk rather than censoring it owing to its potential causal effect on the outcome of interest.

We also did a subgroup analysis according to antidepressant class, age category, sex, type of intracranial haemorrhage, comorbidity, and co-medication. We did subgroup analysis using a single model with interaction terms to see whether the association with the concurrent use of NSAIDs among antidepressant users differed significantly. We used the SAS statistical application program (release 9.3) for all statistical analyses. We considered a two tailed value of $\mathrm{P}<0.05$ to be statistically significant.

\section{Results}

From the 7555863 people who received prescriptions for at least one antidepressant drug during the study period, we identified 5835835 new users of antidepressants. A total of 5168833 people met the study inclusion criteria. After propensity score estimation and matching in a one to one ratio, the cohort used in the analysis of antidepressant with NSAIDs versus without NSAIDs included 4145226 people. The c statistic was 0.686 . The figure shows the cohort selection process. Among 5168833 people who used the antidepressant and NSAIDs combination, the mean follow-up was 18 (SD 8) days and the median was 14 (range 2-30; interquartile range 12-28).

Table 1 shows the baseline characteristics of people with antidepressant use with and without NSAIDs in the overall cohort and propensity based matched cohort. All of the standardised difference scores in the propensity based matched cohort were less than 0.1 as an absolute value.

Table 2 shows the hazard ratios for intracranial haemorrhage associated with the use of NSAIDs compared with no use of NSAIDs in antidepressant treated patients. We found that the risk of intracranial haemorrhage was higher for the combined use of antidepressants and NSAIDs than for antidepressant use without NSAIDs (hazard ratio 1.6, 95\% confidence interval 1.32 to 1.85). We found no statistically meaningful differences in risk of intracranial haemorrhage between the antidepressant drug classes. The differences in adjusted hazard ratios for tricyclic antidepressants (1.7 (1.33 to 2.13) $v 1.6$ (1.27 to 2.03)), selective serotonin reuptake inhibitors (1.4 (1.17 to 1.72) v 1.5 (1.27 to 1.86$)$ ), and serotonin-norepinephrine reuptake inhibitors (0.4 (0.32 to $0.46) v 1.5$ (1.31 to 1.83$)$ ), each compared with the rest, were not statistically significant. The $\mathrm{P}$ values greater than 0.05 for subgroup analysis of different antidepressant classes showed that no particular class increased the risk of intracranial haemorrhage.

Table 3 shows the risk of intracranial haemorrhage in subgroups according to age, sex, subtype of intracranial haemorrhage, comorbidity, and co-medication. We found no difference in risk associated with age and subtype. The hazard ratio associated with concomitant use of NSAIDs was higher among male than female patients (2.6 (1.93 to 3.42) $v 1.2$ (0.89 to 1.57)). Comorbidities and co-medications did not seem to increase the risk of intracranial haemorrhage with combined use of antidepressants and NSAIDs.

\begin{tabular}{|c|c|c|c|c|c|c|c|c|c|}
\hline \multirow[b]{2}{*}{ Subgroup } & \multicolumn{3}{|c|}{ Antidepressants only } & \multicolumn{3}{|c|}{ Antidepressants + NSAIDs } & \multicolumn{2}{|c|}{ Hazard ratio $(95 \% \mathrm{Cl})$} & \multirow[b]{2}{*}{$P$ value } \\
\hline & $\begin{array}{l}\text { Sum of } \\
\text { person years }\end{array}$ & $\begin{array}{l}\text { No of } \\
\text { events }\end{array}$ & $\begin{array}{l}\text { Incidence rate per } 1000 \\
\text { person years* }(95 \% \mathrm{Cl})\end{array}$ & $\begin{array}{l}\text { Sum of } \\
\text { person years }\end{array}$ & $\begin{array}{l}\text { No of } \\
\text { events }\end{array}$ & $\begin{array}{l}\text { Incidence rate per } 1000 \\
\text { person years* }(95 \% \mathrm{Cl})\end{array}$ & Unadjusted & Adjustedt & \\
\hline Overall & 106858 & 169 & $1.6(1.36$ to 1.84$)$ & 99978 & 573 & $5.7(5.28$ to 6.22$)$ & 1.9 (1.69 to 2.24$)$ & 1.6 (1.32 to 1.85$)$ & $<0.001$ \\
\hline \multicolumn{10}{|c|}{ Antidepressant exposure } \\
\hline TCA & 37803 & 57 & $1.5(1.16$ to 1.95$)$ & 53017 & 307 & 5.8 (5.18 to 6.48$)$ & $2.2(1.75$ to 2.66$)$ & 1.7 (1.33 to 2.13$)$ & \multirow{2}{*}{$0.770 \ddagger$} \\
\hline The rest & 69055 & 112 & $1.6(1.35$ to 1.95$)$ & 46961 & 266 & $5.7(5.02$ to 6.39$)$ & 2.3 (1.86 to 2.83$)$ & 1.6 (1.27 to 2.03$)$ & \\
\hline SSRI & 27165 & 35 & $1.3(0.93$ to 1.79$)$ & 12002 & 82 & $6.8(5.50$ to 8.48$)$ & 3.4 (2.86 to 3.98$)$ & 1.4 (1.17 to 1.72$)$ & \multirow{2}{*}{$0.678 \ddagger$} \\
\hline The rest & 79693 & 134 & $1.7(1.42$ to 1.99$)$ & 87977 & 491 & 5.6 (5.11 to 6.10$)$ & 2.5 (2.14 to 2.98$)$ & 1.5 (1.27 to 1.86$)$ & \\
\hline SNRI & 3255 & 14 & $4.3(2.55$ to 7.26$)$ & 2715 & 12 & $4.4(2.51$ to 7.78$)$ & 0.5 (0.43 to 0.58$)$ & 0.4 (0.32 to 0.46$)$ & \multirow{2}{*}{$0.190 \neq$} \\
\hline The rest & 103603 & 155 & $1.5(1.28$ to 1.75$)$ & 97264 & 561 & $5.8(5.31$ to 6.27$)$ & 2.3 (2.02 to 2.70$)$ & 1.5 (1.31 to 1.83$)$ & \\
\hline \multicolumn{10}{|c|}{$\begin{array}{l}\text { SNRI=serotonin-norepinephrine reuptake inhibitors (including duloxetine, milnacipran, and venlafaxine); SSRI=selective serotonin reuptake inhibitors (including citalopram, escitalopram, } \\
\text { fluoxetine, fluvoxamine, paroxetine, and sertraline); TCA=tricyclic antidepressants (including amitriptyline, amoxapine, clomipramine, dothiepin (dosulepin), imipramine, nortriptyline, and } \\
\text { quinupramine). } \\
\text { *Incidence rate=(No of events/sum of person years) } \times 1000 ; 95 \% \text { Cl calculated assuming Poisson distribution. } \\
\text { tAdjusted for dementia, warfarin, heparin group, and steroids as time varying covariates, using matched Cox regression models; death was treated as competing risk. } \\
\text { fP value for interaction. }\end{array}$} \\
\hline
\end{tabular}


Table 3 | Subgroup analyses of risk of intracranial haemorrhage with combined use of antidepressants and nonsteroidal anti-inflammatory drugs (NSAIDs), compared with antidepressants use without NSAIDs, in propensity based matched cohort

\begin{tabular}{|c|c|c|}
\hline Subgroup & Hazard ratio $(95 \% \mathrm{Cl})^{*}$ & $P$ value for interaction \\
\hline \multicolumn{3}{|l|}{ Age } \\
\hline$<45$ years $(n=1285011)$ & $2.2(1.24$ to 3.80$)$ & \multirow{2}{*}{0.234} \\
\hline$\geq 45$ years $(n=2860215)$ & $1.5(0.87$ to 2.67$)$ & \\
\hline \multicolumn{3}{|l|}{ Sex } \\
\hline Male $(n=1600710)$ & $2.6(1.93$ to 3.42$)$ & \multirow{2}{*}{$<0.001$} \\
\hline Female $(n=2544516)$ & $1.2(0.89$ to 1.57$)$ & \\
\hline \multicolumn{3}{|l|}{ Subtype of intracranial haemorrhage $(n=4145226)$} \\
\hline Subarachnoid haemorrhage $(160)(n=262)$ & $1.3(1.05$ to 1.52$)$ & \multirow{3}{*}{$\dagger$} \\
\hline Intracerebral haemorrhage (161) $(n=313)$ & $1.3(1.08$ to 1.55$)$ & \\
\hline Other non-traumatic intracranial haemorrhage $(162)(n=167)$ & $1.3(1.08$ to 1.57$)$ & \\
\hline \multicolumn{3}{|l|}{ History of comorbidities in previous year } \\
\hline \multicolumn{2}{|l|}{ Diabetes: } & \multirow{3}{*}{0.002} \\
\hline Yes $(n=521696)$ & $1.1(0.86$ to 1.30$)$ & \\
\hline No $(n=3623530)$ & $1.9(1.53$ to 2.29$)$ & \\
\hline \multicolumn{2}{|l|}{ Chronic obstructive pulmonary disease: } & \multirow{3}{*}{0.003} \\
\hline Yes $(n=620779)$ & $3.7(3.13$ to 4.46$)$ & \\
\hline No $(n=3524447)$ & $1.4(1.21$ to 1.72$)$ & \\
\hline \multicolumn{2}{|l|}{ Hypertension: } & \multirow{3}{*}{$<0.001$} \\
\hline Yes $(n=1107587)$ & $1.0(0.80$ to 1.30$)$ & \\
\hline No $(n=3037639)$ & $2.4(1.87$ to3.03) & \\
\hline \multicolumn{2}{|l|}{ Dyslipidaemia: } & \multirow{3}{*}{0.455} \\
\hline Yes $(n=154933)$ & $2.1(1.75$ to 2.46$)$ & \\
\hline No $(n=3990293)$ & $1.5(1.30-1.84)$ & \\
\hline \multicolumn{2}{|l|}{ Osteoarthritis: } & \multirow{3}{*}{0.052} \\
\hline Yes $(n=849327)$ & $1.2(0.98$ to 1.44$)$ & \\
\hline No $(n=3295899)$ & $1.7(1.42$ to 2.10$)$ & \\
\hline \multicolumn{2}{|l|}{ Rheumatoid arthritis: } & \\
\hline Yes $(n=81271)$ & $0.2(0.18$ to 0.25$)$ & 0.010 \\
\hline No $(n=4063955)$ & $1.6(1.38$ to 1.94$)$ & \\
\hline Osteoporosis: & & \\
\hline Yes $(n=321711)$ & 0.8 (0.69 to 0.98$)$ & 0.009 \\
\hline No $(n=3823515)$ & $1.7(1.42$ to 2.04$)$ & \\
\hline Alcohol related disorder: & & \\
\hline Yes $(n=75057)$ & $1.7(1.40$ to 1.98$)$ & 0.868 \\
\hline No $(n=4070169)$ & $1.6(1.31$ to 1.86$)$ & \\
\hline Ischaemic heart disease: & & \\
\hline Yes ( $n=223039)$ & $0.8(0.69$ to 0.99$)$ & $<0.001$ \\
\hline No $(n=3922187)$ & 1.8 (1.48 to 2.13$)$ & \\
\hline Chronic kidney disease: & & \\
\hline Yes $(n=56031)$ & $0.5(0.43$ to 0.60$)$ & 0.026 \\
\hline No $(n=4089195)$ & $1.6(1.38$ to 1.94$)$ & \\
\hline Peptic ulcer: & & \\
\hline Yes $(n=772740)$ & $1.1(0.90$ to 1.32$)$ & 0.023 \\
\hline No $(n=3372486)$ & 1.7 (1.43 to 2.08$)$ & \\
\hline Non-alcoholic liver disease: & & \\
\hline Yes $(n=364689)$ & $1.6(1.38$ to 1.97$)$ & 0.823 \\
\hline No $(n=3780537)$ & $1.6(1.30$ to 1.86$)$ & \\
\hline Neoplasm: & & \\
\hline Yes $(n=611623)$ & $1.5(1.22$ to 1.78$)$ & 0.692 \\
\hline No $(n=3533603)$ & $1.6(1.32$ to 1.93$)$ & \\
\hline Heart failure: & & \\
\hline Yes $(n=44616)$ & $9.9(8.30$ to 11.68$)$ & 0.071 \\
\hline No $(n=4100610)$ & $1.5(1.28$ to 1.80$)$ & \\
\hline Disease of arteries: & & \\
\hline Yes $(n=262085)$ & $0.6(0.47$ to 0.66$)$ & 0.021 \\
\hline No $(n=3883$ 141) & $1.6(1.38$ to 1.95$)$ & \\
\hline Disease of veins: & & \\
\hline Yes $(n=210315)$ & $1.0(0.84$ to 1.18$)$ & 0.149 \\
\hline No ( $n=3934$ 911) & $1.6(1.36$ to 1.93$)$ & \\
\hline
\end{tabular}




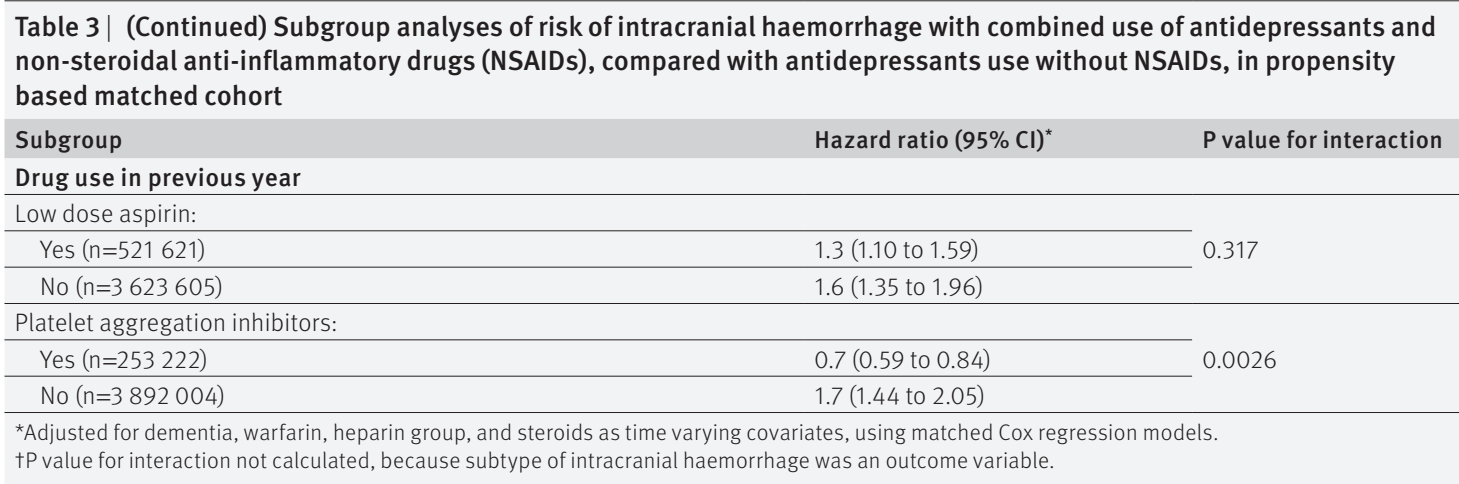

\section{Discussion}

In this population based cohort study, we evaluated the association between the combined use of antidepressants and NSAIDs, compared with the use of antidepressants alone, and the risk of intracranial haemorrhage. Compared with the use of antidepressants alone, the combined use of antidepressants and NSAIDs was associated with an increased risk of intracranial haemorrhage.

\section{Comparison with other studies}

These results are in line with those of a nested casecontrol study of the risk of intracranial haemorrhage in users of selective serotonin reuptake inhibitors, which found a trend towards an increased risk of intracranial haemorrhage in people with current exposure to both selective serotonin reuptake inhibitors and NSAIDs. ${ }^{10}$ The odds ratio of intracranial haemorrhage for current use of selective serotonin reuptake inhibitors and never use of NSAIDs was 0.7 (95\% confidence interval 0.3 to 1.7 ) and the odds ratio for current use of both drug types was 2.4 (0.9 to 6.2), compared with never use of either drug type. Our study included all the classes of antidepressants, and we found no difference between them.

Advancing age and antithrombotic agents are well known risk factors for intracranial haemorrhage, ${ }^{10} \quad 12$ but the hazard ratio for intracranial haemorrhage associated with the combined use of antidepressants and NSAIDs did not differ significantly in the patients who used antithrombotic agents or in older patients. The combined use of antidepressants and NSAIDs seems not to have had a major effect on patients who already had risk factors for intracranial haemorrhage. However, male sex was the most common risk factor for a higher hazard ratio for intracranial haemorrhage with combined use of antidepressants and NSAIDs. We verified our study design by including myocardial infarction, which is not related to bleeding. The endpoint not related to bleeding did not increase the risk of intracranial haemorrhage compared with the endpoints related to bleeding (hazard ratio $0.9,0.65$ to 1.32 ). Our results showed that the study design was adequate to detect the increase in risk of bleeding with combined use of antidepressant and NSAIDs (data not shown).

Antidepressants, particularly selective serotonin reuptake inhibitors, block platelet uptake, and use of these agents results in bleeding complications. ${ }^{5}$ NSAIDs are also known to inhibit normal platelet function. ${ }^{6}$ However, a previous population based study did not find a significant association of use of each drug with intracranial haemorrhage. ${ }^{13}$ Our study found the additional effect according to the drug-drug interaction based on the population based data. Serotonin-norepinephrine reuptake inhibitors work by inhibiting the reuptake of not only serotonin but also norepinephrine. Elevation of norepinephrine concentrations may be associated with an increased risk of intracranial haemorrhage. A high risk with venlafaxine was reported by De Abajo and Garcia-Rodriguez, who estimated the risk of upper gastrointestinal tract bleeding. ${ }^{24}$ This may be because, as they noted, venlafaxine has a lower affinity for the serotonin receptor than do most selective serotonin reuptake inhibitors, ${ }^{25}$ but to compensate for its lower potency in vitro, a threefold to sevenfold greater daily dose is usually prescribed.

To the best of our knowledge, this is the first population based cohort study focusing on the risk of intracranial haemorrhage associated with the combined use of antidepressants and NSAIDs. Most existing studies have been case-control studies and have focused on abnormal bleeding risk from selective serotonin reuptake inhibitors. This study included all antidepressant prescriptions in Korea during a five year period. We focused on changes in risk due to addition of NSAIDs to antidepressants, which could provide information about drug interaction.

\section{Strengths and limitations of study}

Our finding should be interpreted with caution. This study has potential inaccuracy of coding and incompleteness of records. The outcome measures were also limited to patients admitted to hospital with intracranial haemorrhage, which does not capture events outside hospital. However, patients with fatal events are likely to be in hospital, which minimises the possibility of us missing fatal cases. A validation study compared the diagnosis derived from the Health Insurance Review and Assessment Service database with the actual diagnosis in patients' medical records in Korea. The overall positive predictive value of the diagnoses was $83.4 \%$ in the case of patients admitted to hospital. ${ }^{16}$ Computed tomography and magnetic resonance imaging are routinely used in the diagnosis of intracranial haemorrhage, and a radiologist's reading is required for 
insurance claims in Korea. ${ }^{26}$ According to a nationwide survey of 152 representative hospitals, computed tomography or magnetic resonance imaging was used in $89 \%$ of hospital admissions for intracranial haemorrhage. Agreement on diagnosis of intracranial haemorrhage is generally high in Korea and in other countries. ${ }^{16}$ 26-30 We defined death by ICD-10 codes (I46.1, I46.9, R96, R98, and R99) without further records after the date of coding.

Our findings are subject to selection bias and confounding with respect to the relative difference in the baseline for the risk of intracranial haemorrhage between the comparison groups. However, we used propensity score matching, which should eliminate a greater proportion of the baseline differences than would stratification or covariate adjustment. Although we used a propensity score matched design, this does not preclude findings being influenced by potential confounders. Hidden bias may remain because of the influence of unmeasured confounders.

\section{Conclusion}

The addition of NSAIDs to antidepressant treatment increased the risk of intracranial haemorrhage within 30 days of the combination starting, especially in men. This result adds to evidence confirming the increase of risk with combination use of antidepressants and NSAIDs. Special attention is needed when patients use both these drugs together.

We thank staff at the Health Insurance Review and Assessment Service for their assistance with data acquisition and Jocelyn Graf from Proficia for English proofreading

Contributors: All authors contributed to the study design and interpretation of data. S-HC and MJP had the main responsibility for statistical analysis, but all authors contributed. J-YS, MJP, and SHL wrote the manuscript, and all authors reviewed and commented on drafts and approved the final manuscript and the decision to submit for publication. J-YS is the guarantor.

Funding: This research received no specific grant from any funding agency in the public, commercial, or not for profit sector.

Competing interests: All authors have completed the ICMJE uniform disclosure form at www.icmje.org/coi_disclosure.pdf and declare: no support from any organisation for the submitted work; no financial relationships with any organisations that might have an interest in the submitted work in the previous three years; no other relationships or activities that could appear to have influenced the submitted work.

Ethical approval: This study was approved by the institutional review board of the Korea Institute of Drug Safety and Risk Management, Seoul (study ID: KIDS-IRB-2013-007)

Data sharing: No additional data available.

Transparency declaration: The lead author (the manuscript's guarantor) affirms that the manuscript is an honest, accurate, and transparent account of the study being reported; that no important aspects of the study have been omitted; and that any discrepancies from the study as planned (and, if relevant, registered) have been explained.

This is an Open Access article distributed in accordance with the Creative Commons Attribution Non Commercial (CC BY-NC 4.0) license, which permits others to distribute, remix, adapt, build upon this work non-commercially, and license their derivative works on different terms, provided the original work is properly cited and the use is noncommercial. See: http://creativecommons.org/licenses/by-nc/4.0/.

1 Moussavi S, Chatterji S, Verdes E, et al. Depression, chronic diseases, and decrements in health: results from the World Health Surveys. Lancet 2007;370:851-8.

2 Osborn DP, Fletcher AE, Smeeth L, et al. Factors associated with depression in a representative sample of 14217 people aged 75 and over in the United Kingdom: results from the MRC trial of assessment and management of older people in the community. Int J Geriatr

Psychiatry 2003;18:623-30.
3 Anglin R, Yuan Y, Moayyedi P, et al. Risk of upper gastrointestinal bleeding with selective serotonin reuptake inhibitors with or without concurrent nonsteroidal anti-inflammatory use: a systematic review and meta-analysis. Am J Gastroenterol 2014;109:811-9.

4 Warner-Schmidt JL, Vanover KE, Chen EY, et al. Antidepressant effects of selective serotonin reuptake inhibitors (SSRIs) are attenuated by antiinflammatory drugs in mice and humans. Proc Natl Acad Sci U S A 2011;108:9262-7.

5 Skop BP, Brown TM. Potential vascular and bleeding complications of treatment with selective serotonin reuptake inhibitors. Psychosomatics 1996;37:12-6.

6 Schafer Al. Effects of nonsteroidal anti-inflammatory therapy on platelets. Am J Med 1999;106:25-36S.

7 Loke YK, Trivedi AN, Singh S. Meta-analysis: gastrointestinal bleeding due to interaction between selective serotonin uptake inhibitors and non-steroidal anti-inflammatory drugs. Aliment Pharmacol Ther 2008;27:31-40.

8 Huang ES, Khalili H, Strate LL, et al. Selective serotonin reuptake inhibitors and risk of gastrointestinal bleeding in two prospective, population-based cohorts. Gastroenterology 2011:1:S137.

9 Abajo F, Gil M, Bryant V, et al. Upper gastrointestinal bleeding associated with NSAIDs, other drugs and interactions: a nested case-control study in a new general practice database. Eur / Clin Pharmacol 2013;69:691-701.

10 Bak S, Tsiropoulos I, Kjaersgaard JO, et al. Selective serotonin reuptake inhibitors and the risk of stroke: a population-based case-control study. Stroke 2002;33:1465-73.

11 De Abajo FJ, Jick H, Derby L, et al. Intracranial haemorrhage and use of selective serotonin reuptake inhibitors. BrJ Clin Pharmacol 2000;50:43-7.

12 Kharofa J, Sekar P, Haverbusch M, et al. Selective serotonin reuptake inhibitors and risk of hemorrhagic stroke. Stroke 2007;38:3049-51.

13 Johnsen SP, Pedersen L, Friis S, et al. Nonaspirin nonsteroidal anti-inflammatory drugs and risk of hospitalization for intracerebral hemorrhage: a population-based case-control study. Stroke 2003;34:387-91

14 Kwon SM. Payment system reform for health care providers in Korea. Health Policy Plan 2003;18:84-92.

15 Shin JY, Choi NK, Jung SY, et al. Overlapping medication associated with healthcare switching among Korean elderly diabetic patients. Korean Med Sci 2011;26:1461-8.

16 Park BJ, Sung JH, Park KD, et al. Report of the evaluation for validity of discharged diagnoses in Korean health insurance database. Seoul National University, 2003:19-52.

17 Katzung BG, Masters SB, Trevor AJ. Basic and clinical pharmacology. 12th ed. McGraw-Hill, 2012

18 Quan H, Sundararajan V, Halfon P, et al. Coding algorithms for defining comorbidities in ICD-9-CM and ICD-10 administrative data. Med Care 2005;43:1130-9

19 Reducing bias in a propensity score matched-pair sample using greedy matching techniques. Proceedings of the Twenty-sixth Annual SAS Users Group international conference; 2001. SAS Institute, 2001.

20 A unified approach to measuring the effect size between two groups

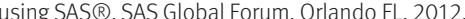

21 Austin PC. Using the standardized difference to compare the prevalence of a binary variable between two groups in observational research. Commun Stat Simul C 2009;38:1228-34

22 Austin PC. The use of propensity score methods with survival or timeDtoDevent outcomes: reporting measures of effect similar to those used in randomized experiments. Stat Med 2014;33:1242-58.

23 Andersen PK, Geskus RB, de Witte T, et al. Competing risks in epidemiology: possibilities and pitfalls. Int J Epidemiol 2012;41:861-70

24 De Abajo FJ, Garcia-Rodriguez LA. Risk of upper gastrointestinal tract bleeding associated with selective serotonin reuptake inhibitors and venlafaxine therapy: interaction with nonsteroidal anti-inflammatory drugs and effect of acid-suppressing agents. Arch Gen Psychiatry 2008:65:795-803.

25 Tatsumi M, Groshan K, Blakely RD, et al. Pharmacological profile of antidepressants and related compounds at human monoamine transporters. Eur J Pharmacol 1997;340:249-58

26 Jung SY, Choi NK, Kim JY, et al. Short-acting nifedipine and risk of stroke in elderly hypertensive patients. Neurology 2011;77:1229-34.

27 Korean Ministry of Health and Welfare. Pilot test of National Cardiovascular Disease Surveillance System. Ministry of Health and Welfare, 2000

28 Krarup LH, Boysen G, Janjua $\mathrm{H}$, et al. Validity of stroke diagnoses in a national register of patients. Neuroepidemiology 2007;28:150-4

29 Leppala JM, Virtamo J, Heinonen OP Validation of stroke diagnosis in the National Hospital Discharge Register and the Register of Causes of Death in Finland. Eur J Epidemiol 1999;15:155-60.

30 Liu L, Reeder B, Shuaib A, et al. Validity of stroke diagnosis on hospital discharge records in Saskatchewan, Canada: implications for stroke surveillance. Cerebrovasc Dis 1999;9:224-30.

C BMJ Publishing Group Ltd 2015 